\title{
Clinical Spectrum and Outcome of Empyema in Nepalese Children
}

\author{
Bhatta NK¹, Singh AP², Kalakheti $B^{3}$, Khanal $B^{4}$, Shrestha $P^{5}$, Singh $\mathbf{R}^{6}$ \\ ${ }^{1}$ Dr. Nisha Keshary Bhatta, Associate Professor, Department of Pediatrics \& Adolescent Medicine, ${ }^{2}$ Dr. Akshay \\ Pratap Singh, Associate Professor, Department of Surgery, ${ }^{3}$ Dr. Balkrishna Kalkheti, Assistant Professor, Department \\ of Pediatrics \& Adolescent Medicine, ${ }^{4}$ Dr. Basudha Khanal, Associate Professor, Department of Microbiology, ${ }^{5}$ Dr. \\ Pramod Shrestha, Assistant Professor, Department of Pediatrics \& Adolescent Medicine, ${ }^{6}$ Prof. Rupa Singh. Department \\ of Pediatrics \& Adolescent Medicine. B. P. Koirala Institute of Health sciences (BPKIHS) Dharan, NEPAL
}

Address for Correspondence: Dr. Nisha Keshary Bhatta. E-mail: nishakesharybhatta@yahoo.com

\begin{abstract}
Introduction: Empyema thoracis in children can be a common entity as a result of complications following pneumonia in children. Studies regarding this complication in children of this country are lacking. Aim: This study was undertaken to determine the clinical presentation and outcome of empyema in children admitted in a tertiary care hospital of eastern Nepal. Methods: this was a prospective study in which all children admitted with pleural effusion during January 2005 to June 2006 were included. History, Chest X-Rays and Pleural Fluid were examined. Appropriate management was done and results compiled. Results: During the study period of eighteen months the most common presenting features were dyspnoea followed by high grade fever, cough and chest pain. The fluid culture was positive in 5(12.8\%) and out of which $4(80 \%)$ was staphylococcus areus. Parental antibiotics and chest tube drainage was successful in $32(84 \%)$ children. Conclusion: The identification of the causative organism in empyema is difficult necessitating the use of empirical antibiotic therapy. Inter costal Chest Tube drainage in particular cases and antibiotics are useful for immediate and long term outcome.
\end{abstract}

Key words: Empyema, chest tube drainage, decortication

\section{Introduction}

Pleural effusion is associated with $40 \%$ of bacterial pneumonia and $60 \%$ of effusion result into formation of empyema in all age groups., ${ }^{1,2}$ Pleural empyema continues to be serious problem in developing countries despite the availability of different modalities of treatment. Empyema thoracis in children can be common as a result of is high annual incidence of pneumonia i.e. $90 / 1000$ in children $<5$ years. ${ }^{3}$ Even with this high incidence the clinical spectrum of these patients and systematic study regarding their outcome are lacking in Nepalese children. This study gives a brief overview of the clinical spectrum and outcome of children with empyema admitted at in a tertiary care hospital of Eastern Nepal.

\section{Materials and Methods}

All children with admitted with pleural effusion during January 2005 and June 2006 in the department of paediatrics at the B. P. Koirala Institute of Health
Sciences, (BPKIHS ) hospital in Eastern Nepal were prospectively included in this study. For the purpose of the study, cases of empyema were defined by presence of frank pleural pus or para-pneumonic exudates with high polymorphs or presence of organism with clinicoradiological evidence of pleural effusion. The basic investigations, chest radiography, pleural fluid analysis, culture and blood culture were done in all the cases. Ultra-sonography or C.T. Scan of chest was done in selected cases only. All cases except those having multiloculated cysts were managed with chest tube drainage. Along with intravenous antibiotics and supportive treatments; namely maintenance of hydration, oxygenation, nutrition etc. Chest tube was removed after clinical improvement i.e. when no drainage was documented for more than 24 hours. Cases that showed definite multiseptations, bronchopleural fistula or non-improvement with previous regimen were subjected to thoracotomy surgery. Patients were discharged after clinical recovery, with oral antibiotics whenever needed. And a regular follow up was advised. 


\section{Results}

During the study period of eighteen months there were thirty nine (39) children who were admitted with empyema. The male to female (M: F) ratio was 2:1 with the age ranging from 3-14 years (mean: 7years.) The male children with empyema were admitted twice as many times as compared to female children. Persistent high fever (75\%), dyspnoea (85\%), cough (70\%) and chest pain $(25 \%)$ were common features. (Table;1). Right sided pleural involvements were more common (59\%) than left (33\%) and almost 7.7\% had bilateral involvement of the chest. Associated consolidation was seen in $8(20.5 \%)$ children and pneumotoceles in $3(7.7 \%)$ as shown in Table2. Blood or pleural fluid culture showed growth only in (15\%), Staphylococcus aureus being the commonest isolate.

Majority of the children $(60 \%)$ had already received a course of antibiotics for variable period of time before hospitalizations. Some improved with chest tube drainage, whereas some $(18 \%)$ needed thoracotomy decortication. The decortications were done in those children who had multiloculated effusion or had persistent pleural sepsis even after 10 days of tube drainage. In one child decortications was done at admission for multiloculated effusion because had presented late (Table; 3). Empirical intravenous antibiotics were administered to all cases, (Crystalline Penicillin and Cloxacillin) Treatment was modified subsequently (by adding Ceftriaxone and Aminoglycoside) depending upon culture sensitivity result or clinical condition of the child. Mean duration of total therapy (I.V. and oral) was 14 days. All the patients had improved clinically and radio- logically at the time of discharge.

Table 1: Showing Baseline Characteristics of Children with Pleural Empyema

\begin{tabular}{|l|r|r|}
\hline Characteristics & Number & Percentage (\%) \\
\hline Sex (M:F) & $26: 13(2: 1)$ & \\
\hline Age & 16 & 41 \\
\hline 1-5 years & 18 & 46 \\
\hline$>5-10$ years & 5 & 13 \\
\hline$>10$ years & 17 \\
\hline Duration of fever \\
\hline$<7$ days & 9 & 43.6 \\
\hline 8-14 days & 13 & 23.1 \\
\hline$>14-21$ days & 30 & 33.3 \\
\hline Fever & 27 & 75 \\
\hline Cough & 10 & 70 \\
\hline Chest pain & 33 & 25 \\
\hline Dyspnoea & & 85 \\
\hline
\end{tabular}

Table 2: Showing the Radiological findings

\begin{tabular}{|l|c|c|}
\hline Side of Involvement & Number & Percentage\%) \\
\hline Right Sided Empyema & 23 & 59 \\
\hline Left Sided Empyema & 13 & 33.3 \\
\hline Bilateral Empyema & 3 & 7.7 \\
\hline Additional radiological findings \\
\hline Consolidation & 8 & 20.5 \\
\hline Pneumatoceles & 3 & 7.7 \\
\hline
\end{tabular}

Table 3: Showing Various Modalities of Treatment and Outcome

\begin{tabular}{|l|c|c|}
\hline Treatment Received & Number & Percentage (\%) \\
\hline $\begin{array}{l}\text { Parental Antibiotics } \\
\text { and Tube Thoracotomy }\end{array}$ & 38 & 97.5 \\
\hline Decortication & 1 & 2.5 \\
\hline Tube and Decortication & 6 & 15.4 \\
\hline $\begin{array}{l}\text { Total Surgical } \\
\text { Treatment }\end{array}$ & 7 & 18 \\
\hline Bronchopleural Fistula & 1 & 2.5 \\
\hline
\end{tabular}

\section{Discussion}

We have described contemporary clinical presentation and demographics of children presenting with parapneumonic effusion and empyema at a large tertiary care hospital in a developing country.

In our study, male children were more likely to be admitted as compared to female children. Clinical presentation of our study population closely resembled with other similar studies with high fever $(75 \%)$, dyspnoea $(85 \%)$, cough $(70 \%)$ and chest pain $(25 \%)$ as common presenting features. These were likely to be related to various complications associated with community acquired pneumonia like necrotizing pneumonia, pleural effusion, pleural empyema, and lung abscess. ${ }^{4-7}$

Staphylococcus aureus was the commonest isolate, a similar finding reported from the tropics and subtropics. ${ }^{5-13}$ In the tropical zone, excessive sweating and moist skin favours growth of cutaneous flora, leading to a high incidence of staphylococcal pyoderma. Haematogenous spread from these lesions has been suggested as an important mechanism which might be risk factors for pneumonia and parapneumonic empyema. Our finding also reflects need of adding the an anti-staphylococcal agent like Cloxacillin in first-line treatment of severe pneumonia to reduce the morbidity and the mortality. ${ }^{13}$ Reported diagnostic yield from pleural and/or blood culture is low in our study as compared other similar studies, this could 
be explained by the fact that majority of the children had already received course of antibiotics for variable period of time before hospitalizations. Most children respond well to continuous closed tube drainage supported by conservative management. This modality was very effective in causing clinical and radiological improvement within 24 hours. Our study also suggests that the pleural space should be drained for lung reexpansion, relief of respiratory distress, and to prevent formation of thick pleural peel. Results of our finding also bear similarities with other recent series from developing countries which mention thoracocentesis is likely to be inadequate for patients presenting late in the fibropurulent and the organizing phase, where full thoracotomy with decortication remains the treatment of choice. ${ }^{13}$

In Summary, we conclude that identification of the causative agent in children with empyema is often difficult, necessitating the use of empiric rather than specific therapy, where inter Costal Chest Tube Drainage followed by conservative treatment with anti-staphyloccoccal antibiotic is the treatment of choice. Early surgical intervention may have its advantages in loculated empyema, but chest tube drainage seems to be simpler, cost effective and the immediate and long term outcome is satisfactory in most of the cases of non-loculated empyema in resource poor settings of developing countries.

\section{References}

1. Strange C. Pathogenesis And Management of Parapneumonic Effusions and Empyema. In: Feigin RD (ed). UpToDate Pediatrics. Wellesley, MA: UpToDate; 2001.

2. Givan DC, Eigen H. Common Pleural Effusions in Children. Clin Chest Med. 1998; 19:363-371.

3. Nepal Ministry of Health, Department of Health Services Annual Report 2000 - 2001.
4. Chan PWK, Crawford O, Wallis C, Dinwiddie R. Treatment of Pleural Empyema. J Paediatr Child Health 2006; 36, 375-377

5. Kerem E, Ziv YB, Rudenski B, et al. Bacteremic Necrotizing Pneumococcal Pneumonia in Children. Am J Respir Crit Care Med. 1994;149:242-244

6. Taryle DA, Potts DE, Sahn SA. The Incidence and Clinical Correlates of Para-Pneumonic Effusions in Pneumococcal Pneumonia. Chest. 1978; 74:170-173.

7. Murphy D, Lockhart CH, Todd JK. Pneumococcal Empyema. Am J Dis Child. 1980; 134: 659-662.

8. Maziah W, Choo KE, Ray JG, et al. Empyema Thoracis in Hospitalised Children In Kelantan, Malaysia. J Trop Pediatr 1995; 41:185-8.

9. Mangete EDO, Kombo BB, Legg-Jack TE. Thoracic Empyema: A Study of 56 Patients. Arch Dis Child 1993; 69:587-8.

10. Mishra OP, Das BK, Jain AK, et al. ClinicoBacteriological Study of Empyema Thoracis in Children. J Trop Pediatr 1993; 39:380-1.

11. Asindi AA, Efem SE, Asuquo ME. Clinical and Bacteriological Study on Childhood Empyema in South Eastern Nigeria. East Afr Med J 1992; 69:78-82.

12. Ghosh S, Chakraborty CK, Chatterjee BD. ClinicoBacteriological Study of Empyema Thoracis in Infants and Children. J Indian Med Assoc 1990; 88:189-90.

13. Barnawal AK, Singh M, Marwaha RK, Kumar L. Empyema thoracis: A 10-Year Comparative Review of Hospitalized Children From South Asia. Arch Dis Child 2003; 88:1009-14. 